\title{
B-mode ultrasound, color Doppler, and sonoelastography in differentiation between benign and malignant cervical lymph nodes with special emphasis on sonoelastography
}

\author{
Ehab Ali Abdelgawad ${ }^{1 *}$, Manal F. Abu-samra', Nasr Mohammed Abdelhay ${ }^{1}$ and Hoda Mokhtar Abdel-Azeem²
}

\begin{abstract}
Background: Enlarged cervical lymph nodes are the most commonly encountered neck lumps. Ultrasonography is the most extensively used tool for classification of superficial lymph nodes due to its availability and low cost. Ultrasound (US) elastography refers to a non-invasive imaging technique that can describe tissue displacement (i.e., strain) or stiffness in response to a given force.

The aim of this study is to compare between B-mode sonography, color Doppler, and sonoelastography in assessment of enlarged deep cervical lymph nodes.

Results: The prevalence of benign lymph nodes was 26 out of 84 (31\%). Lymphomatous lymph nodes were 22/84 (26.2\%), while metastatic lymph nodes were 36/84 (42.8\%). Color Doppler evaluation of nodal vascular pattern was of high sensitivity (91.7\%), specificity (80.8\%), and accuracy (88.6\%) for differentiating metastatic and benign nodes ( $P$ value was $<0.001)$. There was a significant difference between elasticity scores of benign and malignant lymph nodes $(P<0.001)$. The most frequent score in the malignant group was $3(21 / 27)(77.8 \%)$ while the most frequent score in the benign group was $2(5 / 11)(45.5 \%)$. The mean strain ratio (strain index) for malignant lymph nodes (mean $3.2 \pm 0.8$ ) was significantly greater than that for benign lymph nodes (mean $1.1 \pm 0.8$ ).

Conclusion: Ultrasound elastography with its high sensitivity and specificity is a helpful improvement in US for the assessment of cervical lymph nodes, in which biopsies should be performed.
\end{abstract}

Keywords: Lymph nodes, Ultrasound, Elastography

\section{Background}

Enlarged cervical lymph nodes are the most commonly encountered neck lumps [1]. Various imaging techniques including ultrasonography, computed tomography (CT), and magnetic resonance imaging (MRI) are used to evaluate the possible characteristics of lymph nodes [2]. Ultrasonography is the most extensively used tool for

\footnotetext{
* Correspondence: Abdelgawadehab77@gmail.com

'Department of Radiology, Faculty of Medicine, Minia University, Minia, Egypt Full list of author information is available at the end of the article
}

classification of superficial lymph nodes due to its availability and low cost. Ultrasound elastography (UE) is easy, rather cheap, and quick to perform, well tolerated by patients, and offers a strong diagnostic power [3]. Ultrasound (US) elastography refers to a non-invasive imaging technique that can describe tissue displacement (i.e., strain) or stiffness in response to a given force [4, 5]. Elasticity is a mechanical tissue characteristic that prevents tissue displacement under pressure. It varies in different types of tissue (fat, collagen, and so forth) and in the same tissue in different pathological states

\section{Springer Open}

() The Author(s). 2020 Open Access This article is licensed under a Creative Commons Attribution 4.0 International License, which permits use, sharing, adaptation, distribution and reproduction in any medium or format, as long as you give appropriate credit to the original author(s) and the source, provide a link to the Creative Commons licence, and indicate if changes were made. The images or other third party material in this article are included in the article's Creative Commons licence, unless indicated otherwise in a credit line to the material. If material is not included in the article's Creative Commons licence and your intended use is not permitted by statutory regulation or exceeds the permitted use, you will need to obtain permission directly from the copyright holder. To view a copy of this licence, visit http://creativecommons.org/licenses/by/4.0/. 
(inflammatory, malignant) [6]. Stiff tissues tend to deform less and show less strain than compliant tissues in response to the same imparted force [5].

The aim of this study was to compare between Bmode sonography, color Doppler, and sonoelastography in assessment of enlarged cervical lymph nodes with pathological correlation.

\section{Methods}

Study was approved by the ethical committee. A written consent was obtained for the current study, and the procedure was explained for each patient. In the current study, the diagnostic accuracy of conventional US, Color Doppler ultrasound, and US elastography, as well as the sensitivity and specificity to diagnose malignant cervical lymph nodes such as those caused by lymphoma and metastasis in addition to benign conditions as TB and non-specific lymphadenitis were analyzed.

This prospective study was conducted on 55 patients, 33 males, and 22 females (age ranged from 9 to 68 years with mean age of about 42 years). Inclusion criteria for the examined 55 patients included patients with clinically enlarged cervical lymph nodes including patients with newly diagnosed head and neck cancer. None of the examined patients had received any specific treatment (chemotherapy or radiotherapy) prior to the examination. Necrotic nodes were excluded.

\section{Imaging procedures and equipment}

All patients underwent ultrasound examination, color Doppler scanning and US Elastography using TOSHIBA APLIO 500 ultrasound machine (Toshiba Medical Systems Corporation, Japan) with $8-12 \mathrm{MHz}$ linear probe. Patients were subjected to FNAC, core biopsy, and excisional biopsy according to patient's condition, followed by histopathological examination.

\section{Imaging analysis and interpretation Real-time ultrasound}

Conventional B-mode Examination included the entire neck, looking for abnormal cervical lymph nodes and any abnormal masses. The following US features of cervical lymph nodes were analyzed: shape, short-axis diameter, margin, echogenicity echogenic hilum (present or absent), necrosis, calcifications, and matting.

B-mode US criteria for diagnosis included short-axis diameter, shape, border, long-to-short-axis diameter ratio in the longitudinal plane (L/S), hilum, and echogenicity. Short-axis diameter $<8 \mathrm{~mm}$ was the criterion as benign and $\geq 8 \mathrm{~mm}$ as malignant; regular shape was the criterion as benign and irregular sharp as malignant; regular border was considered as benign and irregular or blurred border as malignant; oval shape (L/S $\geq 2$ ) was considered as benign and round $(<2)$ as malignant; presence of hilum was considered as benign and absent as malignant; homogeneous echogenicity was considered as benign and heterogeneous echogenicity as malignant.

Color Doppler imaging Vascularity of each node was seen in color Doppler ultrasound and ranked from I-IV: type I was defined as a hilar or central flow, type II had peripheral flow only, type III had mixed peripheral flow with central flow, and type IV was defined as no visible flow.

\section{US elastography}

US elastography was performed using the strain method. The target lesion was manually compressed by the transducer under light repetitive pressure followed by decompression and repeated until a stable image was obtained.

Real-time elastographic and B-mode images simultaneously appeared as a two-panel image, in which the elastogram appears in a region-of interest (ROI) box. The elastography images were obtained with the elasticity color map, superimposed on the B-mode images, and displayed on the left side of a dual-display image while the corresponding $\mathrm{B}$-mode image was on the right in order to maintain continuous real-time visualization. The elastography strain images were displayed on color mapping. The red area was the area with the greatest strain (softest component); green area, average strain (intermediate component); and blue area, no strain (stiffest component).

Image interpretation was done using a well expert head and neck radiologist with a 15-year experience and was blinded to clinical and laboratory data. Strains of lymph node and surrounding muscles were measured on elastogram, and the muscle-to-lymph node ratio (strain ratio/index) was calculated. Strain ratio curves and value were calculated automatically by the machine. Afterwards, elastographic images were given 1-4 elasticity scores based on a study by Ying et al. [7]. Offline postprocessing of the acquired elastograms was done using computer software for analysis of pictures called "ImageJ." It calculated the percentage of blue areas of the elastograms (representing the percentage of stiff tissue).

The US elastography assessment was categorized as probably benign (elasticity scores of 1 with total blue area $<10 \%$, moderately soft (total blue area between $10 \%$ and $45 \%$ ), suspicious for malignancy (elasticity score 3 interpreted as moderately stiff with a total blue area between $46 \%$ and $80 \%$ and score 4 which were interpreted as stiff nodes with a total blue area $>80 \%$.

\section{Pathologic diagnosis}

Fine needle aspiration cytology (FNAC) was used in 12 nodes (3 patients), core needle biopsy (CNB) in 52 nodes 
(46 patients), and surgical excisional biopsy in 12 nodes (3 patients). In 3 patients ( 8 lymph nodes), the follow-up after empirical treatment revealed improvement of the enlarged lymph nodes both clinically and radiologically with no recurrence on follow-up and were considered non-specific lymphadenitis.

\section{Statistical analysis of the data}

Data were referred to the computer and analyzed using IBM SPSS software package version 20.0. Qualitative data were described using number and percent. Quantitative data were described using range (minimum and maximum), mean, standard deviation, and median. Significance of the obtained results was judged at the 5\% level. Chi-square test for categorical variables was used to compare between different groups.

Fisher's exact or Monte Carlo correction for chisquare when more than $20 \%$ of the cells have expected count less than 5 , Student's $t$ test for normally quantitative variables, to compare between two studied groups, and Mann-Whitney test for abnormally quantitative variables, to compare between two studied groups. Agreement of the different predictives with the outcome was used and was expressed in sensitivity, specificity, positive predictive value, negative predictive value, and accuracy. Odd ratio (OR) was used to calculate the ratio of the odds and $95 \%$ confidence interval of an event occurring in one risk group to the odds of it occurring in the non-risk group. ROC curve of ES and SR in isolation and combined for prediction of malignancy (Fig. 1).

\section{Results}

Age range for both benign and malignant patients was 9-68 years; the mean age was higher for malignant cases (58 \pm 14.4 years) than for benign cases ( $15.7 \pm 10$ years).

According to pathological results, the prevalence of benign lymph nodes was 26 out of 84 (31\%), of which 20 LN were non-specific lymphadenitis and TB lymphadenitis was detected in 6 LNs (Figs. 2 and 3). Lymphomatous lymph nodes were detected in 22 nodes (26.2\%) (Fig. 4), while metastatic lymph nodes were $36 / 84$ (42.8\%) (Fig. 5).

Among the 36 metastatic lymph nodes, 11 lymph nodes were secondary to thyroid cancer, followed by nasopharyngeal and laryngeal cancer, each accounting for 9 and 10 lymph nodes, respectively. Also, five lymph nodes were histopathologically diagnosed to be secondary to breast cancer and one lymph node was metastatic from tongue cancer.

According to the B-mode sonographic criteria, the short-axis diameter and ratio between the long-axis/ short-axis diameter, both were found to be of no statistical significance $(P>0.05)$. Echogenic hilum was observed in $72.7 \%$ of the benign lymph nodesand in none of the malignant lymph nodes $(P<0.001)$. Out of the examined benign lymph nodes, $90.9 \%$ showed regular margin, while $51.9 \%$ of the examined malignant lymph nodes had irregular outlines (Table 1).

According to the Doppler findings, benign lymph nodes showed hilar vascularity in 19/26 lymph nodes and peripheral vascularity in $7 / 26$ lymph nodes. On the other hand, malignant lymph nodes exhibited peripheral

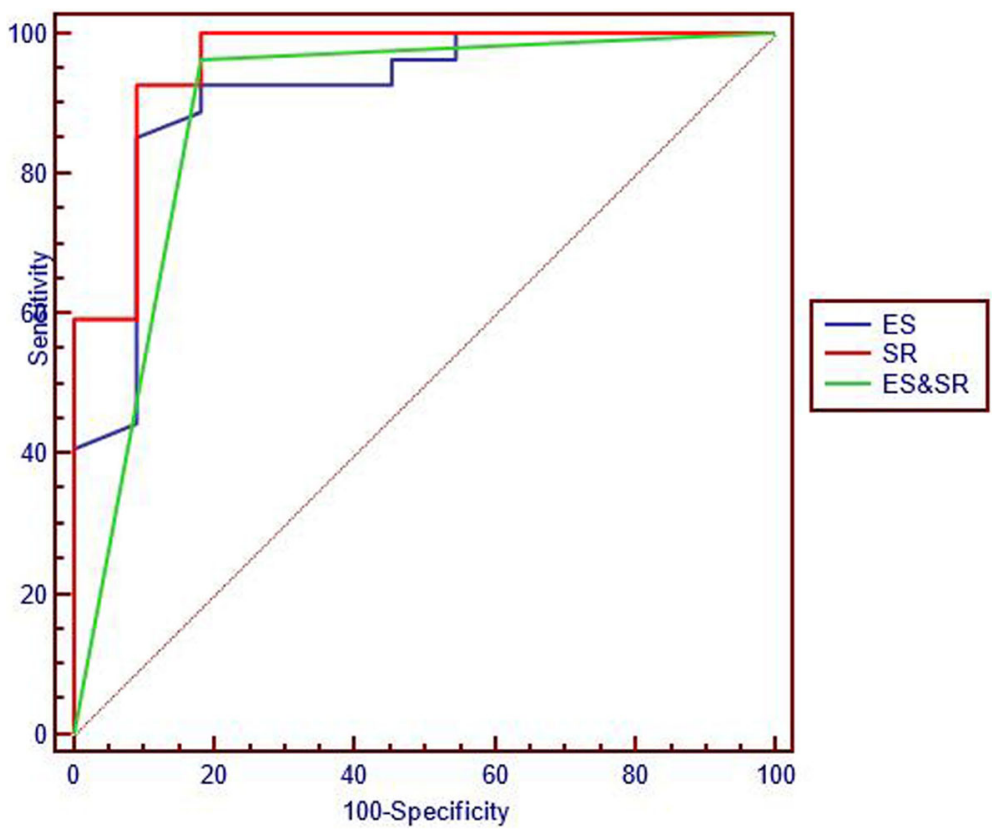

Fig. 1 ROC curve of ES and SR in isolation and combined for prediction of malignancy 


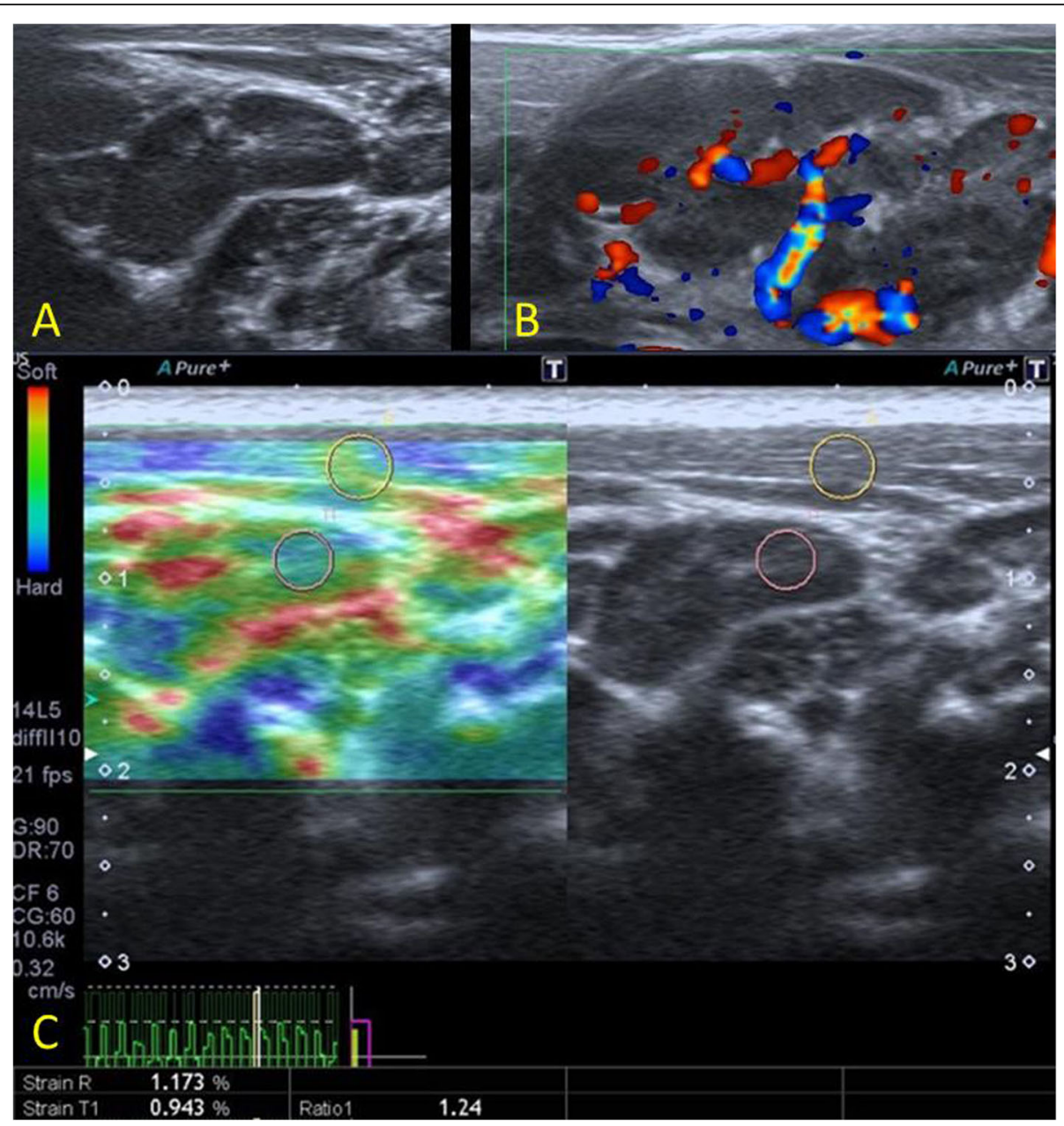

Fig. 2 B-mode US (a) revealed a well-defined, hypoechoic, oval right upper deep cervical lymph node with preserved hilum, L/S ratio was 2.54. Color Doppler (b) revealed central hilar internal vascularity. The split-screen US elastogram (c) of the same lymph node revealed type 1 color pattern, strain ratio value was 1.17. Histopathological evaluation revealed non-specific lymphadenitis

vascularity in 33/58 lymph nodes, mixed vascularity in 5 lymph nodes, and avascular pattern in 20/58 lymph nodes.

Color Doppler ultrasonography evaluation of nodal vascular pattern was of high sensitivity $(93.4 \%)$, specificity (84.7\%), and accuracy (89\%) for differentiating metastatic and benign nodes. Its $P$ value was $<0.001^{*}$.

\section{Qualitative elastographic findings (elasticity score)}

There was a significant difference between elasticity scores of benign and malignant lymph nodes $(P<0.001)$. The most frequent score in the malignant group was 3 (46/58) (79.3\%). On the other hand, the most frequent score in the benign group was 2. Patients with scores of 1 and 2 were classified as elastographic-negative, and those with scores 3 and 4 were classified as positive. Fifty-five malignant lymph nodes were elastographicpositive, and 3 were negative (Table 2).

\section{Quantitative elastographic findings (strain ratio)}

The mean strain ratio (strain index) for malignant lymph nodes (mean $3.3 \pm 0.65$ ) was significantly greater than that for benign lymph nodes (mean $1.3 \pm 0.75$ ) as shown in Table 3. Out of the 84 examined lymph nodes, 26 nodes (31\%) assumed to be benign according strain ratio, 23 of them $(88.4 \%)$ were benign (true negative) by histopathology, and 3 of them (11.6\%) were malignant by histopathology (false negative). Meanwhile, 58 lymph nodes seemed to be malignant according to strain ratio, out of which 55 lymph nodes (49.8\%) were confirmed to be malignant by histopathology (true positive) and 3 lymph node were proved to be benign (false positive) (Table 3 ).

Using a cut-off point of more than $47 \%$ for ES and 1.9 for SR, both ES and SR showed excellent discrimination between malignant and benign nodes, area under curve (AUC) showed an excellent test ranged from 0.91, .95, and 0.89 for ES, SR, and both combined, respectively (Tables 4 and 5). 


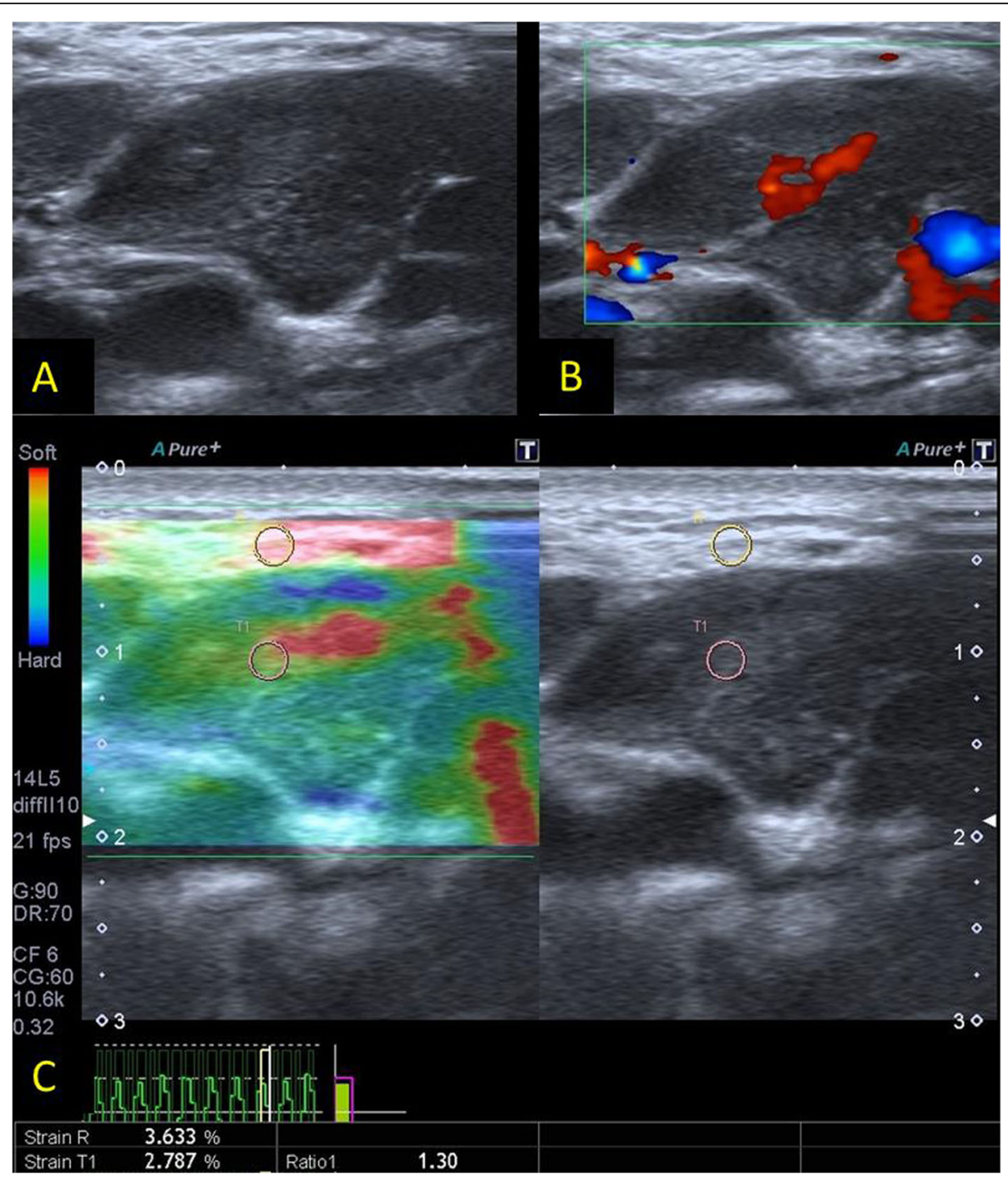

Fig. 3 B-mode US (a) revealed a well-defined hypoechoic left lower deep cervical lymph node with thinned hilum. L/S ratio was 2.5. Color Doppler (b) revealed central hilar vascularity. The split-screen US elastogram (c) revealed type 2 color pattern. Strain ratio value was 3.6. Despite high SR, the final histopathological diagnosis was TB lymphadenitis

\section{Discussion}

Lymphadenopathy is one of the common daily clinical encounters, and it holds high clinical significance as it could be a manifestation of a number of pathological entities [1]. A detailed knowledge of the differential diagnosis of localized or generalized lymphadenopathy is important as lymphadenopathy can be caused by serious conditions such as malignancy.

B-mode sonography, color Doppler sonography, and ultrasound elastography were used in our study to differentiate between benign and malignant cervical lymph nodes in the light of clinical data, follow-up, and histopathological results.

Owing to the multiplicity of lymph nodes, the most suspicious nodes were chosen as the clinical concern was whether the nodal masses are benign or malignant.
Choosing the most suspicious nodes resulted in 84 lymph node groups in 55 patients. Statistical data showed male predominance as $60 \%$ of patients were males and $40 \%$ were females.

Histopathological results showed that $69 \%$ of the lymph nodes (58 lymph nodes) were malignant. This high percentage of malignant lymph nodes in the current study can be attributed to the selection of the most suspicious lymph nodes because physician were worried about metastatic disease in patients with primary malignancy and about being malignant lymphadenopathy such as lymphoma in patients without known primary. This was also observed by Alam et al. [6] and Shi et al. [8], the studies of whom were conducted on 85 lymph nodes, $62 \%$ of which were malignant. However, in some other studies such as 


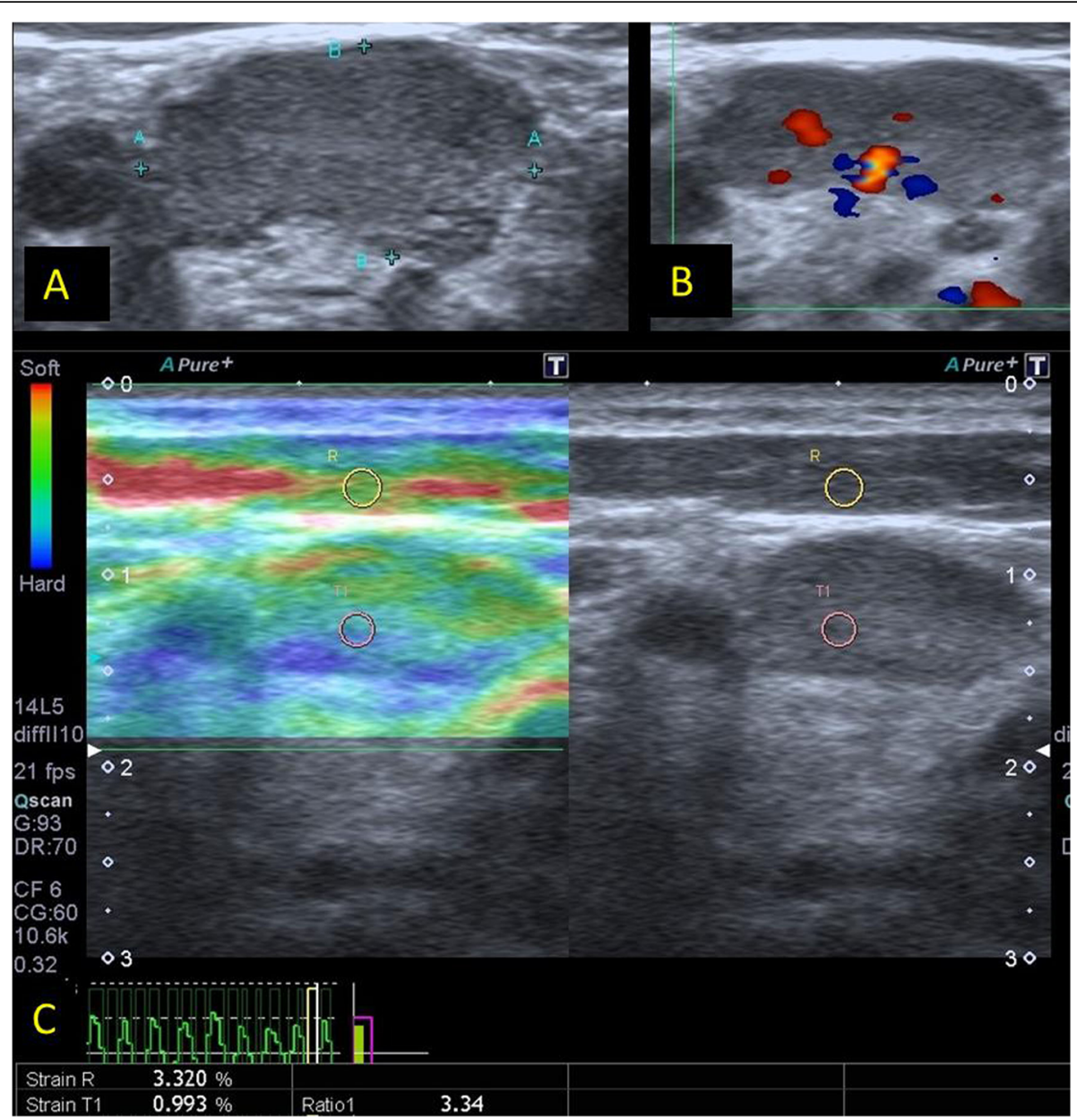

Fig. 4 B-mode US (a) revealed a hypoechoic right lower deep cervical lymph node with irregular outline and lost hilum. L/S ratio was 1.9. Color Doppler (b) revealed a central pattern of internal vascularity. The split-screen US elastogram (c) revealed type 3 color pattern. Strain ratio value was 3.32. The final histopathological diagnosis was nasopharyngeal cancer

that performed by Lyshchik et al. [9], only $43 \%$ of the total of 114 examined lymph nodes were found to be malignant.

The B-mode ultrasonographic diagnosis of lymph nodes has been the topic of many studies in the literature $[10,11]$.

Unlike Teng et al. [12] found that the best B-mode criterion was short-axis diameter with sensitivity of $94 \%$ and accuracy of $71.9 \%$, the current study results showed that the best conventional ultrasound criterion was the presence or absence of a hyperechoic hilum. In the current study, we observed a lost hilum in $100 \%$ of malignant lymph nodes and $27 \%$ of benign nodes. On the other hand, some authors have reported that a hyperechoic hilum can be visualized in up to $51.5 \%$ of metastatic nodes [13], regarding short-axis diameter, results showed that it was statistically insignificant in differentiation between benign and malignant cervical lymph nodes, with a $P$ value of 0.315 .
In the current study, the shape of lymph nodes was not a sufficient reliable indicator for identifying malignant lymph nodes $(P$ 0.121). In contrast, the observations of Toriyabe et al. [14] and Lyshchik et al. [9] showed that $68 \%$ and $82 \%$ of benign nodes respectively were oval and $81 \%$ and $75 \%$ of malignant nodes respectively were round in shape

Normal and reactive nodes were predominantly hypoechoic when compared to the adjacent muscles, however, metastatic nodes from papillary carcinoma of the thyroid are usually hyperechoic. The hyperechogenicity of the lymph nodes is believed to be due to the intra-nodal deposition of thyro-globulin originating from the thyroid primary tumor $[15,16]$.

Regarding color Doppler US, it has been shown that benign lymph nodes tend to show hilar vascularity $(73 \%$ of benign lymph nodes). In contrast, malignant lymph nodes had peripheral $(56.8 \%)$ or mixed (both peripheral and hilar) vascularity (8.6\%). In their study, Teng et al. 


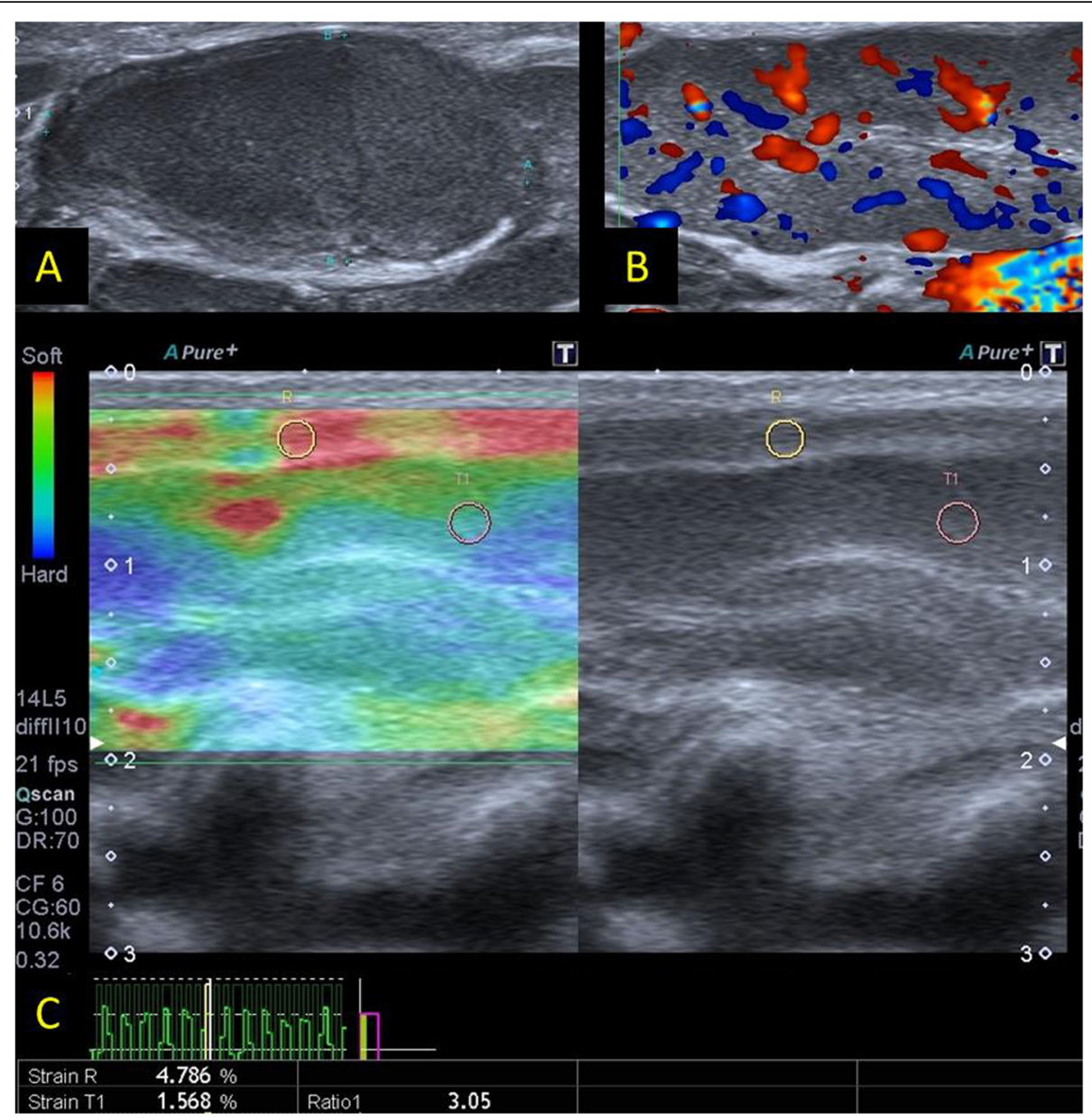

Fig. 5 B-mode US (a) revealed a well-defined hyporechoic left lower deep cervical lymph node with bulky cortex and thinned-out hilum. L/S ratio was 2.2. Color Doppler (b) revealed profuse mixed central and peripheral internal vascularity. The split-screen US elastogram (c) revealed type 3 color pattern. Strain ratio value was 4.7. The final histopathological diagnosis was non-Hodgkin lymphoma

Table 1 Relation between the five used B-mode ultrasound criteria and final histopathological diagnosis

\begin{tabular}{|c|c|c|c|c|}
\hline & & \multicolumn{2}{|c|}{ Histopathology } & \multirow[t]{3}{*}{$P$ value } \\
\hline & & Benign & Malignant & \\
\hline & & $N=26$ & $N=58$ & \\
\hline (1) Short-axis diameter & $\begin{array}{l}\text { Range } \\
\text { Mean } \pm S D\end{array}$ & $\begin{array}{l}4.5-17.6 \mathrm{~mm} \\
9.2 \pm 3.3\end{array}$ & $\begin{array}{l}6.7-27.4 \mathrm{~mm} \\
11 \pm 3.8\end{array}$ & 0.218 \\
\hline (2) L/S ratio (long- to short-axis diameter ratio) & $\begin{array}{l}\text { Range } \\
\text { Mean } \pm \mathrm{SD} \\
\text { Median/(IQR) }\end{array}$ & $\begin{array}{l}1.6-3 \\
2.3 \pm 0.5 \\
2.4 /(1.6-2.3)\end{array}$ & $\begin{array}{l}1.3-4.2 \\
1.7 \pm 0.4 \\
1.7(1.5-1.9)\end{array}$ & 0.201 \\
\hline (3) Hilum & $\begin{array}{l}\text { Absent: } n(\%) \\
\text { Present: } n(\%)\end{array}$ & $\begin{array}{l}7(27 \%) \\
19(73 \%)\end{array}$ & $\begin{array}{l}58(100 \%) \\
0(0 \%)\end{array}$ & $<0.001^{*}$ \\
\hline (4) Margin & $\begin{array}{l}\text { Sharp: } n(\%) \\
\text { Irregular: } n(\%)\end{array}$ & $\begin{array}{l}22(90.9 \%) \\
4(9.1 \%)\end{array}$ & $\begin{array}{l}28(49.3 \%) \\
30(51.7 \%)\end{array}$ & $0.028^{*}$ \\
\hline (5) Echogenicity & $\begin{array}{l}\text { Hypo: } n(\%) \\
\text { Hyper: } n(\%)\end{array}$ & $\begin{array}{l}17(65.3 \%) \\
9(34.6 \%)\end{array}$ & $\begin{array}{l}40(68.9 \%) \\
18(31.3 \%)\end{array}$ & 0.134 \\
\hline
\end{tabular}

1 Independent samples $t$ test for parametric quantitative data between the two groups, 2 Mann-Whitney test for non-parametric quantitative data between the two groups, 3 Fisher exact test for qualitative data between the two groups

* Significant level at $P$ value $<0.05$ 
Table 2 Relation between elasticity score and final histopathological diagnosis

\begin{tabular}{|c|c|c|c|c|}
\hline & & \multicolumn{2}{|c|}{ Histopathology } & \multirow[t]{3}{*}{$\boldsymbol{P}$ value } \\
\hline & & Benign & Malignant & \\
\hline & & $N=26$ & $N=58$ & \\
\hline Percentage of the blue (stiff) area & $\begin{array}{l}\text { Range } \\
\text { Mean } \pm \mathrm{SD} \\
\text { Median/(IQR) }\end{array}$ & $\begin{array}{l}8-79 \% \\
22 \pm 18 \% \\
26 /(12-47)\end{array}$ & $\begin{array}{l}10-91 \% \\
57.6 \pm 14.3 \% \\
68 /(49-80)\end{array}$ & $<0.001^{*}$ \\
\hline \multicolumn{5}{|l|}{ Elasticity score (ES) } \\
\hline ES 1 & < 10\%: n (\%) & $9(34.6 \%)$ & $0(0 \%)$ & \\
\hline ES 2 & 10-45\%: n (\%) & $15(57.7 \%$ & $3(5.1 \%)$ & \\
\hline ES 3 & 46-80: n (\%) & $2(7.7 \%)$ & $42(72.4 \%)$ & \\
\hline ES 4 & > 80: $n(\%)$ & $0(0 \%)$ & $13(22.4 \%)$ & \\
\hline
\end{tabular}

Mann-Whitney test for non-parametric quantitative data between the two groups Fisher exact test for qualitative data between the two groups

*Significant level at $P$ value $<0.05$

[12] reported sensitivity $67 \%$, specificity $76 \%$, and accuracy $71 \%$ for Doppler in differentiating benign and malignant LNs. Also, in Lyshchik et al. [10] had found that specificity of Doppler was higher than its sensitivity recording $99 \%$ and $47 \%$, respectively.

Ultrasound elastography corresponds to clinical palpation as a method to assess how stiff lymph nodes are. In general, metastatic lymph nodes are hard and lymph nodes of TB are of tough texture.

Elastography is a technique that uses ultrasound to analyze the stiffness of lymph nodes by measuring the amount of distortion that occurs when the lymph node is subjected to external pressure. The stiffness of the lymph node is closely related to biological characteristics. Malignant lymph nodes often are infiltrated by tumor cells, necrosis, and calcification. Benign lymph nodes, not containing metastatic deposits, have a similar stiffness to normal tissue. According to this theory, malignant lymph nodes are mostly stiffer than benign ones (Bhatia et al. [17]).

Elasticity score is used for the interpretation of elastographic findings [17]. The elasticity scoring system initially proposed by Itoh et al. [18] was useful for comparing breast ultrasound elastographic results, by using five pattern elasticity scores. The four patterns scoring system is the most frequently ES used in

Table 3 Relation between elastographic strain ratio and final histopathological diagnosis

\begin{tabular}{lllll}
\hline & & \multicolumn{2}{l}{ Histopathology } & \multirow{P}{*}{$\boldsymbol{P}$ value } \\
\cline { 3 - 4 } & & Benign & Malignant & \\
& $N=26$ & $N=58$ & \\
\hline Strain & Range & $0.3-2.9$ & $1.6-4.2$ & $<0.001^{*}$ \\
ratio & Mean $\pm \mathrm{SD}$ & $1.2 \pm 0.7$ & $3.3 \pm 0.8$ & \\
(SR) & Median/(IQR) & $1 /(0.5-1.2)$ & $3.3 /(2.5-3.8)$ &
\end{tabular}

Mann-Whitney test for non-parametric quantitative data between the two groups

Fisher exact test for qualitative data between the two groups

* Significant level at $P$ value $<0.05$ detecting lymph nodes abnormalities due to its simplicity [17]. So, we used it in the present study.

Furukawa et al. [19], Iagnocco et al. [20], and Choi et al. [21] carried out studies on lymph nodes and classified the elastographic findings into four patterns. Their results revealed that malignant lymph nodes were found to exhibit patterns 3 and 4 and benign lymph nodes patterns 1 and 2 .

Findings observed in the current study were similar to those of Furukawa et al. [19]. Eighty-two percent of benign lymph nodes that we examined were classified as patterns 1 and 2, while $94 \%$ of malignant ones were classified as patterns 3 and 4 .

Scores 3 and 4 were present in $72.4 \%$ and $22.4 \%$ of the malignant lymph nodes, respectively, $7.72 \%$ and $0 \%$ of the benign lymph nodes, respectively. On the other hand, $5.1 \%(3 / 58)$ of the malignant nodes had score 2 (false negative).

Ying et al. [7] concluded that even though elasticity score measurement had a good diagnostic accuracy, it had significant inter-observer variability. Thus, a quantitative method such as strain ratio measurement was needed for analysis of elasticity of the lymph node.

Different cut-off values of strain index were suggested to differentiate between benign and malignant nodes (1.5 and 1.78) [6,9], while the cut-off value used in Arda et al. [22] was 2.5. In the present study, the cut-off value was 1.9 and after revising the histopathological results, the calculated sensitivity for strain ratio greater than 1.9 was $94.8 \%$, specificity was $88.5 \%$, PPV was $94.8 \%$, NPV was $88.5 \%$, and accuracy was $92.8 \%$. High specificity is the greatest advantage of elastography, which has been found not only in the current study but also in other studies [7, 9, 22, 23]. So, ultrasound elastography can reduce the number of unnecessary biopsy in the diagnosis of metastatic cervical lymph nodes. In a study carried out on 32 enlarged lymph nodes, the authors stated that ultrasound elastography showed sensitivity, specificity, and accuracy of $83.3 \%, 90 \%$, and $87.5 \%$, respectively [24]. 
Table 4 Diagnostic performance of elasticity score and strain ratio in isolation and combined

\begin{tabular}{llll}
\hline & Elasticity score (ES) & Strain ratio (SR) & Combined ES and SR \\
\hline Cut-off point & $>47 \%$ & $>1.9$ & 0.891 \\
AUC & 0.912 & 0.956 & $0.75-0.97$ \\
$\mathbf{9 5 \%}$ Cl & $0.78-0.98$ & $0.84-0.996$ & $<0.001^{*}$ \\
P value & $<0.001^{*}$ & $<0.001^{*}$ & 58 \\
TP & 55 & 55 & 25 \\
TN & 24 & 23 & 1 \\
FP & 3 & 3 & 1 \\
FN & 2 & 3 & $98.3 \%$ \\
Sensitivity & $96.4 \%$ & $94.8 \%$ & $96.1 \%$ \\
Specificity & $88.8 \%$ & $88.5 \%$ & $92.9 \%$ \\
PPV & $95.8 \%$ & $94.8 \%$ & $96.1 \%$ \\
NPV & $92.3 \%$ & $88.5 \%$ & $98.11 \%$ \\
Accuracy & $94.4 \%$ & $92.8 \%$ & \\
\hline AUC ar & & $3 \%$ & \\
\hline
\end{tabular}

$A U C$ area under curve, $C l$ confidence interval, $P P V$ positive predictive value, NPV negative predictive value

The specificity of ultrasound elastography has varied widely among different reports. Some studies showed high specificity of elastography as in the studies performed by Alam et al. [6] and Hefeda et al. [25] (100\% and $95.6 \%$, respectively), who studied the difference between reactive and metastatic lymph nodes. In the current study, sensitivity of elasticity score was $96.4 \%$ and sensitivity of strain ratio was $94.8 \%$. Alam et al. [6] reported the highest accuracy for sonoelastography (89\%) in agreement with our results that showed $94.4 \%$ accuracy for elasticity score and $92.8 \%$ accuracy for strain ratio

On the other hand, Lo et al. [23] in a study included 131 patients, found that the elasticity pattern system had sensitivity of $67 \%$, specificity of $57 \%$, positive predictive value of $52 \%$, and negative predictive value of $71 \%$. They concluded that elastography offers no additional value over conventional ultrasound in predicting malignancy in cervical lymph nodes.

The sonoelastography technique is helpful in differentiating reactive from metastatic lymph nodes, but it did not show the ability to distinguish other situations such as TB. Two patients in our study were diagnosed with TB lymphadenitis. The first one took score 3 (false positive), and the second one score 2. So, ultrasound elastography was equivocal in our results in such situations.

The characteristics of TB on ultrasonography are variable according to clinical stage. The appearance of $\mathrm{TB}$ on ultrasonography was classified into four types: acute inflammation type, cheesy necrosis type, cold abscess type, and calcification type according to some authors such as Zhao et al. [26]. The differential diagnosis between TB and malignant disease of lymph node is always the diagnostic dilemma of ultrasound and sonoelastography. In a study done by Teng et al. [12], only 5 out of 16 lymph nodes of TB were diagnosed correctly by ultrasound elastography, whereas the whole diagnostic accuracy of elastography was $66 \%$ in 89 lymph nodes which were suspected to be malignant.

The current study has some limitations such as the small number of studied nodes. Sonoelastography is a user-dependent technique related to experience of the radiologists. A low-quality elastogram can result in problems in interpretation. A poor-quality elastogram may

Table 5 Sensitivity, specificity, and accuracy of US, Doppler ES, and SR

\begin{tabular}{|c|c|c|c|c|c|c|c|c|c|c|c|c|}
\hline \multirow{3}{*}{ US } & \multicolumn{3}{|l|}{ Sensitivity } & \multicolumn{3}{|l|}{ Specificity } & \multicolumn{3}{|l|}{ Accuracy } & \multicolumn{3}{|l|}{$\boldsymbol{P}$ value } \\
\hline & $\begin{array}{l}\text { Short-axis } \\
\text { diameter }\end{array}$ & $\begin{array}{l}\text { Long- to } \\
\text { short-axis } \\
\text { diameter } \\
\text { ratio }\end{array}$ & Hilum & $\begin{array}{l}\text { Short-axis } \\
\text { diameter }\end{array}$ & $\begin{array}{l}\text { Long- to } \\
\text { short-axis } \\
\text { diameter } \\
\text { ratio }\end{array}$ & Hilum & $\begin{array}{l}\text { Short-axis } \\
\text { diameter }\end{array}$ & $\begin{array}{l}\text { Long- to } \\
\text { short-axis } \\
\text { diameter } \\
\text { ratio }\end{array}$ & Hilum & $\begin{array}{l}\text { Short axis } \\
\text { diameter }\end{array}$ & $\begin{array}{l}\text { Long- to } \\
\text { short-axis } \\
\text { diameter } \\
\text { ratio }\end{array}$ & Hilum \\
\hline & $85 \%$ & $73 \%$ & $100 \%$ & $29 \%$ & $33 \%$ & $72 \%$ & $68 \%$ & $72 \%$ & $92 \%$ & 0.315 & 0.121 & 0.001 \\
\hline Doppler & $93.4 \%$ & & & $84.7 \%$ & & & $89 \%$ & & & $<0.001^{*}$ & & \\
\hline ES & $96.4 \%$ & & & $98.8 \%$ & & & $94.4 \%$ & & & $>0.001^{*}$ & & \\
\hline SR & $93.4 \%$ & & & $95.6 \%$ & & & $94.1 \%$ & & & $<0.001^{*}$ & & \\
\hline Combined ES and SR & $98.3 \%$ & & & $96.1 \%$ & & & $92.9 \%$ & & & $<0.001 *$ & & \\
\hline
\end{tabular}

*Significant level at $P$ value $<0.05$ 
result from pulsation of neighboring vessels. The shape of the neck may result in sliding motion during compression.

A lot of research is still needed to fully understand the varied appearance of diseases and to standardize its application. It is possible that it will become a part of the routine diagnostic sonographic procedure in the near future.

\section{Conclusion}

Ultrasound elastography with its high sensitivity and specificity is a helpful improvement in US for the assessment of cervical lymph nodes, in which biopsies should be performed.

\section{Abbreviations}

MRI: Magnetic resonance imaging; US: Ultrasound.; CT: Computed tomography; UE: Ultrasound elastography; MDCT: Multi-detector computed tomography; FNAC: Fine Needle Aspiration Cytolog

\section{Acknowledgements}

We gratefully acknowledge the hard work, efficiency, and devotion of our imaging technicians, which made this work possible.

\section{Authors' contributions}

EA contributed to the study design, data collection, CT image interpretation, and manuscript drafting. MFA and NMAH contributed to the CT image interpretation, manuscript writing, statistical analysis, and sequence alignment. HM helped in patient referral, manuscript editing, and sequence alignment. All authors read and approved the final manuscript.

\section{Funding}

No sources of funding.

\section{Availability of data and materials}

The datasets used and/or analyzed during the current study are available from the corresponding author on reasonable request.

\section{Ethics approval and consent to participate}

This study was approved by the Research Ethics Committee of the Faculty of Medicine at Minia University in Egypt on 2018 (reference number is not applicable). All patients included in this study gave written informed consent to participate in this research.

\section{Consent for publication}

Consent for publication: All patients included in this research gave written informed consent to publish the data contained within this study.

\section{Competing interests}

The authors declare that they have no competing interests.

\section{Author details}

'Department of Radiology, Faculty of Medicine, Minia University, Minia, Egypt. ${ }^{2}$ Department of Clinical Oncology, Faculty of Medicine, Minia University, Minia, Egypt.

Received: 27 February 2020 Accepted: 28 July 2020

Published online: 18 August 2020

\section{References}

1. Evans R, Ying M, Ahuja A (2003) Ultrasound. In: Ahuja A, Evans R et al (eds) Imaging in head and neck cancer: a practical approach. Greenwich Medical Media Limited, London, pp 3-16

2. Choi HJ, Ju W, Myung SK (2010) Diagnostic performance of computer tomography, magnetic resonance imaging, and positron emission tomography or positron emission tomography/computer tomography for detection of metastatic lymph nodes in patients with cervical cancer: Metaanalysis. Cancer Sci 101(6):1471-1479
3. Bhatia KSS, Lee YYP, Yuen EHY, Ahuja AT (2013) Ultrasound elastography in the head and neck. Part I. Basic principles and practical aspects. Cancer Imaging 13(2):253-259

4. Lerner RM, Huang SR, Parker KJ (1990) "Sonoelasticity" images derived from ultrasound signals in mechanically vibrated tissues. Ultrasound Med Biol 6(3):231-239

5. Konofagou EE (2004) Quo vadis elasticity imaging? Ultrasonics. 2(1):331-336

6. Alam F, Naito K, Horiguchi J (2008) Accuracy of sonographic elastography in the differential diagnosis of enlarged cervical lymph nodes: comparison with conventional B-mode sonography. Am J Roentgenol 191(2):604-610

7. Ying L, Hou Y, Zheng H-M (2012) Real-time elastography for the differentiation of benign and malignant superficial lymph nodes: a metaanalysis. Eur J Radiol 81(10):2576-2584

8. Shi G, Wang X, Ou G (2015) Comparative study of ultrasonic elastography with conventional ultrasonography in cervical lymph nodes. Chin J Ultrasound Med 26(8):730-733

9. Lyshchik A, Higashi T, Asato R (2007) Cervical Lymph Node Metastases: Diagnosis at Sonoelastography —Initial Experience. Radiology 243(1):258-267

10. Ahuja A, Ying M (2002) An overview of neck node sonography. Investig Radiol 37(6):333-342

11. Kessler A, Rappaport Y, Blank A (2003) Cystic appearance of cervical lymph nodes is characteristic of metastatic papillary thyroid carcinoma. J Clin Ultrasound 31(1):21-25

12. Teng $\mathrm{D}$, Wang $\mathrm{H}$, Lin $\mathrm{Y}$ (2012) Value of ultrasound elastography in assessment of enlarged cervical lymph nodes. Asian Pac J Cancer Prev 13(5): 2081-2085

13. Vassallo P, Wernecke K, Roos N (1992) Differentiation of benign from malignant superficial lymphadenopathy: the role of high-resolution US. Radiology 83(1):215-220

14. Toriyabe Y, Nishimura T, Kita S (1997) Differentiation between benign and metastatic cervical lymph nodes with ultrasound. Clin Radiol 52(12):927-932

15. Kouvaraki MA, Shapiro SE, Fornage BD (2003) Role of preoperative ultrasonography in the surgical management of patients with thyroid cancer. Surgery 134(6):946-954

16. Wunderbaldinger P, Harisinghani MG, Hahn PF (2002) Cystic lymph node metastases in papillary thyroid carcinoma. Am J Roentgenol 178(3):693-697

17. Bhatia KS, Cho CC, Yuen Y-H (2010) Real-time qualitative ultrasound elastography of cervical lymph nodes in routine clinical practice: interobserver agreement and correlation with malignancy. Ultrasound Med Biol 36(12):1990-1997

18. Itoh A, Ueno E, Tohno E (2006) Breast disease: clinical application of US elastography for diagnosis. Radiology 239(2):341-350

19. Furukawa MK, Kubota A, Hanamura H (2007) Clinical application of real-time tissue elastography to head and neck cancer--evaluation of cervical lymph node metastasis with real-time tissue elastography. Nihon Jibiinkoka Gakkaikaiho 110(7):503-505

20. Iagnocco A, Kaloudi O, Perella C (2010) Ultrasound elastography assessment of skin involvement in systemic sclerosis: Lights and shadows. J Rheumatol 37(8):1688-1691

21. Choi JJ, Kang BJ, Kim SH (2011) Role of sonographicelastography in the differential diagnosis of axillary lymph nodes in breast cancer. J Ultrasound Med 30(4):429-436

22. Arda K, Ciledag N, Gumusdag P (2006) Differential diagnosis of malignant cervical lymph nodes at real-time ultrasonographicelastography and Doppler ultrasonography. Magyar Radiol Online 6:10-13

23. Lo W-C, Cheng P-W, Wang C-T (2013) Real-time ultrasound elastography: an assessment of enlarged cervical lymph nodes. Eur Radiol 23(9):2351-2357

24. Dawood HA, Hassan TA (2014) Value of combined real time sonoelastography and apparent diffusion coefficient value measurement in differentiation of enlarged neck lymph node. Egypt J Radiol Nuclear Med 45:387-394

25. Hefeda MM, Badawy ME (2014) Can ultrasound elastography distinguish metastatic from reactive lymph nodes in patients with primary head and neck cancers? Egypt J Radiol Nuclear Med 45(3):715-722

26. Zhao Y-W, Jin Z-J, Zheng Y, Sun Z-D (2008) Characteristics and classification of cervical tuberculouslymphadentis on ultrasonography. Shanghai Med Imaging 17:218-219

\section{Publisher's Note}

Springer Nature remains neutral with regard to jurisdictional claims in published maps and institutional affiliations. 